\title{
PENERAPAN QUALITY ASSURANCE PADA PT.XYZ UNTUK PROSES PERENCANAAN MENGGUNAKAN FRAMEWORK COBIT 4.1 DOMAIN PO
}

\section{Quality Assurance Assessment on PT.XYZ for Planning Process Using Framework COBIT 4.1 Domain PO}

\author{
Roby Wijaya ${ }^{1)}$ \\ ${ }^{1)}$ Prodi Magister Manajemen/Program Pascasarjana, Satya Negara Indonesia University \\ Diterima 03 January 2017 / Disetujui 26 January 2018
}

\begin{abstract}
In present day, Information Technology becomes one of the most important thing in life. and IS Audit becomes one of the most commonly used ways of ensuring the quality of Information Technology. Seeing that many of information technology adoption is failed because organization underestimate the planning process. Because of that, information technology in company must be managed and optimized. One of information technology management guidelines is COBIT 4.1 (Control Objectives for Information and Related Technology 4.1) which is separate into 4 domain, and be divided into 34 process. That 4 domain called Plan and Organise (PO), Acquire and Implement (AI), Delivery and Support (DS) and Monitor and Evaluate (ME). Using COBIT 4.1 as information technology management guideline, will be known the level of information technology management in company based on maturity model that has been provided by COBIT 4.1. This research will be focused on domain PO (with exception PO4, PO5, PO7 and PO8) and will be perform on PT.XYZ, whom its field work is IT Consultant and Outsourcing. The overall assessment on domain PO get score 0.8 with the highest score 1.2 on PO1; PO10 and the lowest score 0.5 on PO9. Therefore researcher suggest several recommendation for PT.XYZ to improve the process of planning as the COBIT 4.1 guidelines.

Keywords: Information technology menagement, COBIT 4.1, Plan and Organize, Information System Audit.
\end{abstract}

\begin{abstract}
ABSTRAK
Pada hari ini, teknologi informasi menjadi salah satu hal terpenting dalam kehidupan. Dan audit SI menjadi salah satu cara yang paling sering digunakan dalam memastikan kualitas dari teknologi informasi. Melihat banyak adopsi teknologi informasi yang gagal karena organisasi meremehkan proses perencanaan. Karena itu, teknologi informasi di perusahaan harus dikelola dan dioptimalkan dengan audit SI. Salah satu panduan manajemen teknologi informasi adalah COBIT 4.1 (Control Objectives for Information and Related Technology 4.1) yang terpisah menjadi 4 domain, dan dibagi menjadi 34 proses. Itu 4 domain bernama Plan and Organise (PO), Acquire and Implement (AI), Delivery and Support (DS) dan Monitor and Evaluate (ME). Dengan menggunakan COBIT 4.1 sebagai pedoman manajemen teknologi informasi, akan diketahui tingkat manajemen teknologi informasi di perusahaan berdasarkan model maturity yang telah disediakan oleh COBIT 4.1. Penelitian ini akan difokuskan pada domain PO (dengan pengecualian PO4, PO5, PO7 dan PO8) dan akan dilakukan di PT.XYZ, yang bermain pada bidang IT Consultant and Outsourcing. Penilaian keseluruhan pada domain PO mendapatkan skor 0,8 dengan skor tertinggi 1,2 pada PO1; PO10 dan skor terendah 0,5 pada PO9. Oleh karena itu peneliti menyarankan beberapa rekomendasi kepada PT.XYZ untuk memperbaiki proses perencanaan sebagai pedoman COBIT 4.1.
\end{abstract}

Kata Kunci: Manajemen Teknologi Informasi, COBIT 4.1, Plan and Organise, Audit Sistem Informasi. 


\section{PENDAHULUAN}

Teknologi Informasi (TI) adalah teknologi yang membantu macam-macam instansi untuk mencapai tujuan bisnis dari masing-masing instansi dan mendorong peningkatkan bisnis dari awal dibangunnya instansi tersebut. Dan Tata kelola TI adalah proses dimana tujuan entitas yang memberi dampak pada teknologi informasi disepakati, diarahkan, dan dikendalikan secara maksimal. Lalu, tata kelola TI yang paling efektif selalu dimulai dari tahap pertama yaitu perencanaan guna mengetahui kebutuhan dari organisasi dan implikasi dari kebutuhan ini (Khther \& Othman, 2013).

Sayangnya, ada banyak implementasi implementasi proyek TI/SI yang gagal. Dan salah satu penyebab utama kegagalan tersebut adalah karena kurangnya perencanaan yang memadai. Karena itu, pentingnya proses perencanaan strategis TI juga banyak diutarakan dari penelitian lainnya. Lalu, Berdasarkan pentingnya rencana strategis TI/SI seperti yang dijelaskan pada bagian di atas dan sebagai salah satu dari beberapa rekomendasi yang diajukan oleh penelitian sebelumnya (Harwikarya, et al., 2015) (Sadikin, Hardi, \& Haji, 2014).

PT.XYZ sudah menyadari betul resiko dan kepentingan dari proses perencanaan ini. Oleh karena itu, didalam penelitian ini peneliti akan melakukan proses audit SI untuk melihat kondisi sekarang dari proses perencanaan PT.XYZ menggunakan domain PO dari kerangka kerja COBIT 4.1 dan memberikan rekomendasi dari hasil sekarang yang didapat oleh PT.XYZ.

\section{STUDI PUSTAKA}

\section{IT Governance (ITG)}

ITG memungkinkan sebuah organisasi untuk sepenuhnya memanfaatkan manfaat dari keberadaan informasi yang dimiliki, dan dengan memaksimalkan manfaat, memanfaatkan peluang, mendapatkan keuntungan dalam persaingan. ITG adalah struktur hubungan dan proses yang digunakan untuk mengarahkan dan mengendalikan organisasi untuk mencapai tujuan yang ditetapkan, memberikan nilai lebih dan menjaga keseimbangan antara risiko dan imbal hasil TI dan proses yang berkaitan dengan TI. Ada lima aspek yang menjadi perhatian manajemen dalam mengarahkan dan mengendalikan TI mereka: penyelarasan strategis, pengiriman nilai, manajemen risiko, pengelolaan sumber daya dan manajemen kinerja (ISACA, 2010).

Gartner mendefinisikan tata kelola TI sebagai rangkaian proses yang memastikan penggunaan TI secara efektif dan efisien yang memungkinkan sebuah organisasi mencapai tujuannya. TI merupakan bagian integral dari tata kelola perusahaan dan terdiri dari struktur kepemimpinan dan organisasi dan proses yang memastikan TI organisasi menopang dan memperluas strategi dan sasaran organisasi. Doughty mendefinisikan tata kelola TI sebagai kerangka kerja yang mendukung pengelolaan sumber informasi yang efektif dan efisien (mis., Orang, pendanaan dan informasi) untuk memfasilitasi pencapaian tujuan perusahaan. Fokusnya adalah pada pengukuran dan pengelolaan kinerja TI untuk memastikan bahwa risiko dan biaya yang terkait dengan TI dikontrol dengan tepat. Gartner menyatakan bahwa tata kelola TI membahas dua topik utama: tata kelola permintaan TI (melakukan hal yang benarll) dan tata kelola supply-side IT (menyelesaikan sesuatu dengan benarll). Fokus makalah ini adalah pada kerangka COBIT 5 dan bagaimana hal ini mencakup tata kelola dan pengelolaan TI (Andry, 2016).

\section{Audit Sistem Informasi}

Pada pengertiannya secara garis besar, Audit SI ialah proses pengumpulan dan pengevaluasian bukti-bukti untuk menentukan apakah suatu sistem aplikasi komputerisasi telah menetapkan dan menerapkan sistem pengendalian internal yang memadai, semua aktivitas dilindungi dengan baik/tidak disalahgunakan serta terjaminnya integritas data, keandalan serta 
efektifitas dan efisiensi penyelenggaraan sistem informasi berbasis komputer tersebut (Weber, 1999).

Audit sistem informasi pada hakekatnya merupakan salah satu dari bentuk audit operasional, tetapi kini audit sistem informasi sudah dikenal sebagai satu satuan jenis audit tersendiri yang tujuan utamanya lebih untuk meningkatkan IT governance. Sebagai suatu audit operasional terhadap manajemen sumber daya informasi, yaitu efektivitas, efisiensi, dan ekonomis tidaknya unit fungsional sistem informasi pada suatu organisasi. Dengan diperkenalkan COBIT, kini tujuan audit bukan hanya terbatas pada konsep klasik 3E saja, melainkan kini menjadi: efektivitas, efisiensi, kerahasiaan, keterpaduan, ketersediaan, kepatuhan pada kebijakan/aturan dan keandalan sistem informasi (Weber, 1999).

Dalam pelaksanaannya, jenis audit ini berkembang dalam beberapa variannya: (Weber, 1999)

1. Pemeriksaaan operasional (operational audit) terhadap pengelolaan sistem informasinya, atau lebih tepatnya/tegasnya terhadap tata-kelola teknologi informasi (IT governance),

2. General information review, audit terhadap sistem informasi secara umum pada suatu organisasi tertentu,

3. Audit terhadap aplikasi tertentu yang sedang dikembangkan (quality assurance pada tahap system development).

\section{COBIT 4.1 Framework}

COBIT (Control Objectives for Information and Related Technology) adalah sebuah framework dan supporting toolset yang membantu manajer menjembatani jarak antara tujuan untuk keperluan pengendalian, permasalahan teknik (technical issue) dan resiko bisnis serta mengkomunikasikan level pengendalian kepada stakeholders. COBIT membantu menyokong pengembangan kebijakan yang jelas dan langkah-langkah praktis terbaik yang dapat diambil untuk pengendalian teknologi informasi di seluruh perusahaan. COBIT dirancang antara lain untuk mendukung: (IT Governance Institute, 2007)

1. Manajemen eksekutif dan dewan direksi.

2. Bisnis dan manajemen teknologi informasi.

3. Pengelolaan, assurance, pengendalian dan security professionals.

COBIT telah terbukti memberikan kerangka kerja yang sukses untuk tata kelola TI di lingkungan yang terkendali. Ada empat domain utama dimana ada 34 sasaran kontrol tingkat atas dan tercantum di bawah ini: (Yousif \& Sulaiman, 2015)

1. Plan and Organise (PO),

2. Acquire and Implement (AI),

3. Deliver and Support (DS),

4. Monitor and Evaluate (ME).

Secara lebih rinci, keseluruhan kerangka kerja COBIT dapat ditunjukkan secara grafis, seperti yang digambarkan pada gambar 1. COBIT, dengan model proses COBIT dari empat domain yang berisi 34 proses generik, mengelola sumber daya TI untuk menyampaikan informasi kepada bisnis sesuai dengan persyaratan bisnis dan tata kelola (Andry \& Hartono, 2017).

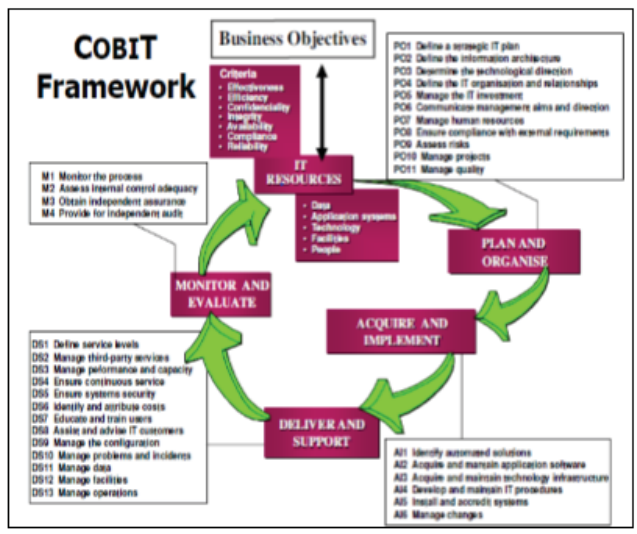

Gambar 1. Kerangka Kerja COBIT 4.1, Sumber: (IT Governance Institute, 2007)

\section{Maturity Level}

Adapun generic maturity model yang digunakan adalah: (IT Governance Institute, 
2007)

- 0 Non-existent - tidak ada sama sekali proses yang terlihat. Perusahaan belum menyadari bahwa ada masalah yang harus dikaji.

- 1 Initial/Ad Hoc - Ada bukti bahwa perusahaan telah menyadari ada masalah yang ada dan harus dikaji namun belum ada standarisasi. Tetapi, ada pendekatan ad hoc yang cenderung diaplikasikan sesuai kasus. Pendakatan manajemen secara umum tidak terstruktur.

- 2 Repeatable but Intuitive - Proses telah dikembangkan pada tahap dimana prosedur yang mirip telah diikuti oleh bermacam-macam orang yang melaksanakan tugas ini. Tidak ada training atau komunikasi secara formal tentang prosedur standar dan tanggung jawabnya jatuh pada individu. Ada ketergantungan yang tinggi pada individu dan sering terjadi error.

- 3 Defined Process - Prosedur telah terstandarisasi dan terdokumentasi, dan komunikasi lewat training. Merupakan keharusan bahwa proses tersebut harus diikuti. Tetapi, sedikit deviasi yang terjadi. Prosedur tersebut tidak rumit tetapi formalisasi dari practice yang sekarang.

- 4 Managed and measurable manajemen memantau dan mengukur kesesuaian dengan prosedur dan mengambil tindakan dimana proses terlihat tidak berjalan efektif. Proses dikembangkan secara berkelanjutan dan memberikan practice yang baik. Otomasi dan alat bantu digunakan dalam cara yang terbatas dan terpecahpecah.

- 5 Optimised - proses telah dirancang sampai tingkat pelaksanaan yang baik, berdasarkan hasil dari pengembangan berkelanjutan dan maturity modelling dengan perusahaan lain. TI digunakan dalam cara terintegrasi untuk mengotomasikan alur kerja, menyediakan alat bantu untuk meningkatkan kualitas dan efektivitas, membuat perusahaan mudah diadaptasi.

\section{METODOLOGI PENELITIAN}

PT. XYZ merupakan perusahaan yang secara bisnis telah berjalan sejak tahun 2000 melalui divisi apisoft (aplikasi integrasi software) dan telah mempunyai pengalaman memberikan solusi teknologi informasi dan jasa professional bagi banyak perusahaan di Indonesia mulai dari skala kecil sampai dengan besar.

Kemampuan dan keberhasilan perusahaan kami dalam memberikan solusi tidak hanya didukung oleh team kami yang solid dimana terdiri dari para professional yang sangat menguasai dibidangnya tetapi juga dari faktor kerjasama dari client kami yang masih terjalin baik sampai dengan saat ini.

Dimulai dari membangun sistem secara tailor made seperti sistem Payroll dan HRD, sistem Koperasi, Sistem Advance accounting, Budget Tracing hingga sampai saat ini kami telah dapat memberikan total solusi teknologi informasi sebagai berikut:

1. Payroll and HR solution

2. Payroll and HR Software

3. Payroll Outsourcing Solution

4. Tailor made Solution

5. Package Solution

\section{Prosedur Penelitian}

Prosedur penelitian yang digunakan seperti langkah-langkah dibawah ini: 


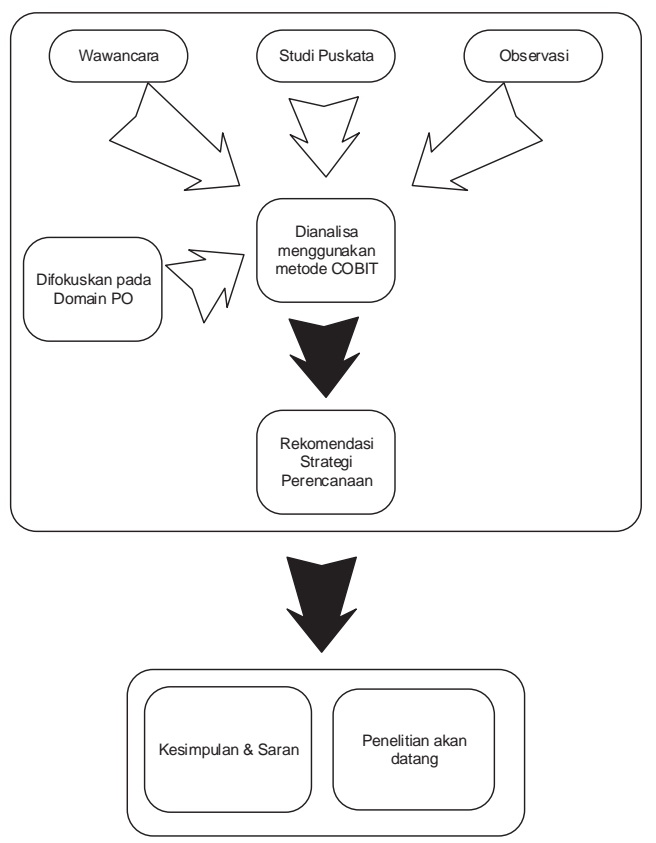

Gambar 2. Prosedur Penelitian

Dari gambar 2, dapat dilihat jika dalam pengerjaan penelitian ini dimulai dengan 3 pengumpulan data utama yaitu, wawancara, studi pustaka dan obsevasi yang dimana hasil dari 3 pengumpulan data tersebut akan di analisa menggunakan kerangka kerja COBIT yang berfokus pada domain PO dan penelitian menghasilkan rekomendasi strategi perencanaan guna mengoptimalkan rencana strategis TI dengan data yang ada. Lalu, di akhiri dengan tahap terakhir yang terdiri dari kesimpulan, saran dan penelitian akan datang.

Untuk lebih detailnya akan dibahas tiap langkah:

1. Tahap Awal:

a. Wawancara, peneliti akan melakukan wawancara kepada orang yang bertanggung jawab akan proses perencanaan pada PT.XYZ guna mendapatkan gambaran mengenai keadaan saat ini.

b. Studi Pustaka, dilakukan untuk mengetahui hal-hal yang berhubungan dengan pengelolaan teknologi informasi menggunakan framework COBIT, serta yang berkaitan dengannya.

c. Observasi, peneliti melakukan observasi didalam dan diluar PT.XYZ tetapi yang masih berkaitan dengan proses perencanaan PT.XYZ secara langsung maupun tidak langsung.

d. Analisa menggunakan metode COBIT 4.1, dari data yang telah terkumpul, peneliti akan melakukan analisa COBIT 4.1 sebagai acuan untuk pembentukan rekomendasi pengembangan untuk strategi perencanaan TI PT.XYZ.

e. Fokus pada domain PO, dalam metode COBIT 4.1 pada proses analisa akan difokuskan pada domain PO yang mengurus masalah perencanaan pada organisasi.

f. Rekomendasi strategi perencanaan, dari analisa COBIT 4.1 yang dilakukan peneliti akan membentuk hasil dari penelitian ini yaitu berupa rekomendasi dari temuan-temuan yang telah dianalisa oleh peneliti.

\section{Tahap Awal:}

a. Kesimpulan \& saran, peneliti akan memberikan kesimpulan dan saran dari hasil penelitian yang telah dilakukan.

b. Penelitian akan datang, peneliti akan memberikan masukanmasukan yang dapat dilakukan untuk penelitian yang akan dating.

\section{HASIL DAN PEMBAHASAN}

Penulis akan menganalisa lebih lanjut ke lingkungan yang terjadi di dalam PT.XYZ, dari karyawan, peralatan, keamanan fisik, peraturan, dan lain-lain. Lalu analisa tersebut akan menggunakan metode COBIT 4.1 dengan fokus ke domain PO.

Plan and Organise (PO), pada tahap ini penulis menganalisis perencanaan strategis TI yang diperlukan untuk mengelola dan mengarahkan semua sumber daya TI sesuai dengan strategi dan prioritas 
bisnis. Fungsi TI dan pemangku kepentingan bisnis bertanggung jawab untuk memastikan bahwa nilai optimal direalisasikan dari portofolio proyek dan layanan. Tingkat kematangan PO yang diharapkan adalah Level 3, Defined Process.

Tabel 1. Hasil Analisa Domain PO1

\begin{tabular}{|c|c|c|}
\hline PO1 & Define a Strategic IT Plan & Score \\
\hline & 1.1 IT value management & 1 \\
\hline & 1.2 Business-IT alignment & 1 \\
\hline & $\begin{array}{l}1.3 \text { Assessment of current } \\
\text { capability and } \\
\text { performance }\end{array}$ & 1 \\
\hline & 1.4 IT strategic plan & 1 \\
\hline & 1.5 IT tactical plans & 1 \\
\hline & $\begin{array}{l}1.6 \text { IT portfolio } \\
\text { management }\end{array}$ & 2 \\
\hline
\end{tabular}

Berikut temuan-temuan mendetail sebagai pendukung hasil analisa diatas:

1. Rencana TI saat ini hanya terbatas pada kegiatan penganggaran TI tahunan berdasarkan instruksi pengembangan sistem yang bersifat ad hoc dengan target penyelesaian pada jangka waktu spesifik.

2. Kegiatan TI mendapatkan arahan dari manajemen untuk keperluan bisnis.

3. Belum ada proses formal untuk menganalisa kemampuan dan kinerja TI saat ini untuk menjawab tantangan bisnis ke depan.

4. Analisa terbatas pada kegiatan per proyek yang dilakukan oleh perusahaan.

5. Rencana strategis TI sudah ditetapkan oleh top management, hanya saja strategi tersebut tidak dituangkan dalam bentuk formal.

6. Rencana TI saat ini hanya terbatas pengembangan sistem yang bersifat ad hoc dengan target penyelesaian pada jangka waktu spesifik, bukan merupakan turunan dari rencana strategis TI.
7. Pengelolaan portofolio investasi TI dilakukan secara tahunan untuk mengawasi jalannya suatu proyek. Tapi ini dilakukan sebagai penyelesaian proyek, bukan pengelolaan.

Tabel 2. Hasil Analisa Domain PO2

\begin{tabular}{llc} 
PO2 & $\begin{array}{l}\text { Define the information } \\
\text { architecture }\end{array}$ & Score \\
\hline & $\begin{array}{l}2.1 \text { Enterprise } \\
\text { information architecture } \\
\text { model }\end{array}$ & 1 \\
& $\begin{array}{l}2.2 \text { Enterprise data } \\
\text { dictionary and data } \\
\text { syntax rules }\end{array}$ & 0 \\
\end{tabular}

\subsection{Data classification $\quad 1$ scheme \\ 2.4 Integrity management 1

Berikut temuan-temuan mendetail sebagai pendukung hasil analisa diatas:

1. Pemodelan arsitektur informasi berjalan secara ad hoc.

2. pengklasifikasian data dan informasi dilakukan secara ad hoc.

3. Tidak terdapat aturan untuk menjamin integritas dan konsistensi data yang tersimpan dalam bentuk elektronis, seperti database, data warehouse, dan data achieves.

4. Semua data yang masuk kedalam bentuk elektronis di perusahaan merupakan tanggung jawab masingmasing karyawan yang me-maintainnya.

Tabel 3. Hasil Analisa Domain PO3

PO3 Determine technological Score direction

$\begin{array}{ll}\begin{array}{l}3.1 \text { Technological } \\ \text { direction planning }\end{array} & 1 \\ \begin{array}{l}3.2 \text { Technological New } \\ \text { infrastructure plan }\end{array} & 1\end{array}$

3.3 Monitoring of future 1 trends and regulations 


\subsection{Technology standards $\quad 1$ \\ 3.5 IT architecture board 0 \\ 0.8}

Berikut temuan-temuan mendetail sebagai pendukung hasil analisa diatas:

1. Untuk pemilihan teknologi dalam perusahaan sendiri ditentukan oleh top management dengan menyesuaikan dengan kebutuhan client.

2. Perencanaan infrastruktur tidak dibuat oleh perusahaan, ini dikarenakan infrastruktur perusahaan yang masih kecil sehingga masih bisa dimaintain secara ad hoc.

3. Manajemen tidak memiliki proses formal untuk mengikuti perkembangan teknologi dan regulasi yang terkait dengan penggunaan teknologi informasi.

4. Untuk pengerjaan implementasi diluat, standar teknologi mengikuti standar teknologi client.

Tabel 4. Hasil Analisa Domain PO6

PO6 Communicate Score management aims and direction

$\begin{aligned} & 6.1 \text { IT policy and control } \\ & \text { environment }\end{aligned}$
$\begin{aligned} & \text { 6.2 Enterprise IT risk and } \\ & \text { control framework }\end{aligned}$

6.3 IT policies
management

6.4 Policy, standards and 1 procedures rollout

\subsection{Communication of IT 1} objectives and direction

Berikut temuan-temuan mendetail sebagai pendukung hasil analisa diatas:

1. Kebijakan dikeluarkan secara reaktif untuk menjawab kasus spesifik yang terjadi.
2. Kebijakan TI belum dibuat, tetapi untuk sosialisasi kebijakan, standar, dan prosedur dilakukan berdasarkan instruksi top mangement.

Tabel 5. Hasil Analisa Domain PO7

PO9 Assess and manage IT Score risks

9.1 IT risk management
framework

9.2 Establishment of risk 1 context

$\begin{array}{ll}\text { 9.3 Event identification } & 0 \\ 9.4 \text { Risk assessment } & 1 \\ 9.5 \text { Risk response } & 1 \\ \text { 9.6 Maintenance and } & 0 \\ \text { monitoring of a risk } & \\ \text { action plan } & \end{array}$

Berikut temuan-temuan mendetail sebagai pendukung hasil analisa diatas:

1. Manajemen belum memiliki proses formal untuk melakukan penilaian risiko TI.

2. Tetapi conteks resiko didefinisikan secara subjektif oleh personil berdasarkan pengalaman individual.

3. Tetapi respon terhadap resiko TI telah didefinisikan secara subjektif oleh personil berdasarkan pengalaman individual.

4. Manajemen TI tidak melakukan pemeliharaan atau evaluasi terhadap resiko-resiko yang dicegah.

Tabel 6. Hasil Analisa Domain PO10

\begin{tabular}{c|lc} 
PO10 & Management Project & Score \\
& $\begin{array}{l}\text { 10.1 Programme } \\
\text { management framework }\end{array}$ & 1 \\
& $\begin{array}{l}\text { 10.2 Project management } \\
\text { framework }\end{array}$ & 1 \\
& $\begin{array}{l}\text { 10.3 Project management } \\
\text { approach }\end{array}$ & 1
\end{tabular}




\begin{tabular}{|c|c|}
\hline $\begin{array}{l}\text { 10.4 Stakeholder } \\
\text { commitment }\end{array}$ & 2 \\
\hline $\begin{array}{l}10.5 \text { Project scope } \\
\text { statement }\end{array}$ & 1 \\
\hline $\begin{array}{l}\text { 10.6 Project phase } \\
\text { initiation }\end{array}$ & 1 \\
\hline $\begin{array}{l}10.7 \text { Integrated project } \\
\text { plan }\end{array}$ & 0 \\
\hline 10.8 Project resources & 1 \\
\hline $\begin{array}{l}10.9 \text { Project risk } \\
\text { management }\end{array}$ & 1 \\
\hline 10.10 Project quality plan & 1 \\
\hline $\begin{array}{l}10.11 \text { Project change } \\
\text { control }\end{array}$ & 1 \\
\hline
\end{tabular}

\subsection{Project planning of 1} assurance methods

10.13 Project performance 2 measurement, reporting and monitoring

\subsection{Project closure} 3

Berikut temuan-temuan mendetail sebagai pendukung hasil analisa diatas:

1. Manajemen TI belum memiliki kerangka kerja formal yang tertulis dan terdokumentasi, Kerangka kerja dilakukan secara adhoc.

2. Pendekatan project dilakukan secara adhoc berdasarkan pengalaman dari personil yang bertanggung jawab atas project tersebut.

3. Sudah ada prosedur untuk dokumentasi komitmen antar stakeholder. Namun belum didefinisikan secara detail.

4. Dokumentasi scope sudah ada. Akan tetapi belum dijelaskan secara detail. Dan dampaknya akan dokumentasi scope yang belum jelas tersebut hanya didefinisikan tergantung pengalaman personil.

5. Untuk project phase tidak dilakukan secara terstruktur. Namun beberapa phase dilakukan berdasakrkan pengalaman individual personil.

6. Project resources sudah dilakukan. Tetapi biasa dilakukan secara adhoc oleh project manager berdasarkan pengalaman individu personil.

7. Manajemen belum menerapkan pengelolaan risiko dalam project pengembangan sistem, inisiatif telah ada namun dalam kasus per kasus.

8. Auditor tidak menemukan adanya perencanaan terhadap kualitas project yang dilakukan. Tetapi kualitas tetap dijaga oleh personil yang melakukan project berdasarkan pengalaman individu personil.

9. Perubahan sistem telah mengikuti proses yang baku, namun terdapat beberapa penyimpangan dari proses tersebut.

10. Auditor tidak menemukan perencanaan metode penjaminan hasil delivery project tersebut. Tetapi penjaminan sudah dilakukan oleh personil yang melakukan project berdasarkan pengalaman individu personil.

11. Project closure telah dilakukan sesuai dengan prosedur dan didokumentasikan. Hanya saja prosedur tersebut tidak dituangkan dalam bentuk formal.

Tabel 7. Hasil Analisa Domain PO

\begin{tabular}{c|lc} 
PO & Plan and Organise & Score \\
\hline & $\begin{array}{l}\text { PO1 Define a strategic IT } \\
\text { plan }\end{array}$ & 1.2 \\
& PO2 Define the information & 0.75
\end{tabular}

PO2 Define the information

0.75 architecture

PO3 Determine

technological direction

PO6 Communicate

management aims and

direction

PO9 Assess and manage IT $\quad 0.5$ risks

PO10 Manage projects 
Dari hasil keseluruhan analisa domain PO yang dilakukan peneliti, maka didapatkan nilai maturity pada PT.XYZ hanya 0.9 atau bisa dikategorikan sebagai Initial/Ad-Hoc. Oleh karena itu, masih jauh dari harapan PT.XYZ yang ingin memiliki nilai maturity sebesar 3.0 atau setingkat dengan Defined Process.

Berikut rekomendasi dari peneliti yang dirangkumkan dari temuan-temuan diatas agar PT.XYZ dapat mencapai nilai maturity yang dinginkan:

1. Membuat prosedur dan kebijakan secara tertulis yang mengatur seluruh proses prencanaan yang berhubungan dengan TI yang telah disetujui oleh semua pihak PT.XYZ, lalu mengkomunikasikannya keseluruh bagian PT.XYZ. Selain itu diperlukan proses dokumentasi yang lengkap.

2. Memiliki dokumentasi dan pencatatan rencana infrastruktur untuk jangka panjang dan jangka pendek.

3. Memiliki dokumentasi pembagian tanggung jawab kerja yang mendetail hingga jabatan terkecil guna menentukan perencanaan.

4. Mengurangi segala jenis pekerjaan yang terlalu bergantung pada individu personil dan penyelesaian yang menggunakan insting.

5. Menbuat portofolio untuk resiko TI agar dari seluruh perencanaan TI dapat dilihat antisipasinya apabila terjadi sesuatu yang tidak diinginkan.

6. Memiliki bagian yang bertugas untuk mengatur kualitas perencanaan TI yang ada di PT.XYZ dan melakukan dokumentasi untuk setiap proses ini.

7. Melakukan pengaturan tentang kepemilikan data dan sistem, serta mendokumentasikan kepemilikan data dan sistem tersebut.

\section{KESIMPULAN DAN SARAN}

\section{Kesimpulan}

Pada bab ini berisikan hasil dari penelitian yang telah dilakukan, maka didapat kesimpulan sebagai berikut:

1. Hasil analisa domain PO pada PT.XYZ menhasilkan nilai maturity sebesar 0.9 atau bisa dikategorikan sebagai Initial/Ad-Hoc. Oleh karena itu, masih jauh dari harapan PT.XYZ yang ingin memiliki nilai maturity sebesar 3.0 atau setingkat dengan Defined Process.

2. Dari hasil analisa tersebut dapat dilihat jika PT.XYZ terdapat kelemahan paling besar pada domain PO9 yaitu Assess and Managed IT Risks yang nilainya hanya 0.5, karena PT.XYZ tidak berpengalaman dalam mengurus resikoresiko TI yang muncul.

3. Dengan adanya hasil penelitian ini PT.XYZ dan perusahaan lainnya agar sadar akan pentingnya perencanaan dalam membangun tata kelola TI.

\section{Saran}

Adapun saran untuk penelitian ini berdasarkan hasil dan kesimpulan, adalah sebagai berikut:

1. Dapat menggunakan domain lain yang terkait dengan perencanaan dalam pembentukan rekomendasi strategi.

2. Memasukkan metode lainnya seperti ISO agar hasil dan rekomendasi lebih bervariatif sehingga dapat disesuaikan dengan kondisi lapangan

\section{DAFTAR PUSTAKA}

Andry, J. F. (2016). Performance Measurement of IT Governance: A Case Study. JSI.

Andry, J. F., \& Hartono, H. (2017). Performance Measurement of IT Based on COBIT Assessment: A Case Study. Association for Information Systems - Indonesia chapter (AISINDO).

Harwikarya, Sadikin, M., Fitrianah, D., Sarinanto, M. M., Nurhaida, I., \& Dwiyanto, A. R. (2015). IS Strategic Plan for Higher Education Based on COBIT Assessment: A Case Study. International Journal of Information and Education Technology. 
ISACA. (2010). CISA Review Manual 2010. Rolling Meadows, IL USA: ISACA.

IT Governance Institute. (2007). COBIT 4.1. USA: ISACA.

Khther, R. A., \& Othman, D. (2013). COBIT Framework As A Guidelines of Effective IT Governance In Higher Education: A Review. International Journal of Information Technology Convergence and Services (IJITCS).

Sadikin, M., Hardi, H., \& Haji, W. H. (2014). IT governance self assessment in higher education Based on COBIT case study: University of Mercu Buana. J. Adv. Manag. Sci.

Weber, R. (1999). Information System Control and Audit. New Jersey: Prentise-hall, Inc.

Yousif, S. T., \& Sulaiman, H. (2015). Conceptual Framework for Successful ITGovernance for EGovernment Services. The 3rd National Graduate Conference. 